\title{
Proposta de aplicativo de wayfinding para a Universidade da Região de Joinville - Univille
}

Proposal of a wayfinding application for the University of the Region of Joinville Univille

BERRI, Maria Eduarda; Acadêmica do curso de Design - Programação Visual; Univille dudaberri1@gmail.com

POZZA, Fernanda; MSc., Orientadora, docente dos cursos de Design e Fotografia da Univille fernanda.costa@univille.br

\section{Resumo}

O presente artigo relata o projeto de iniciação científica, que teve por intuito o desenvolvimento do layout de um aplicativo de wayfinding para smartphone a fim de melhorar a localização e o deslocamento de pessoas na Univille, campus Bom Retiro. O estudo fundamentou-se no Design de Informação, Wayfinding, Design de Interação e Usabilidade. A metodologia utilizada foi a chamada Projeto $E$, voltada para projetos dígito-virtuais. Assim, o desenvolvimento do projeto estruturou-se nas seguintes etapas: (1) Estratégia; (2) Escopo; (3) Estrutura; (4) Esqueleto; (5) Estética; (6) Execução. Como resultado obteve-se um aplicativo conceitual que, se desenvolvido realmente e implementado, pode contribuir para uma melhor orientação dos usuários e visitantes do campus.

Palavras Chave: Design da Informação, Wayfinding, Usabilidade.

\section{Abstract}

This article reports on the scientific initiation project, which aimed to develop the layout of a smartphone wayfinding application in order to improve the location and the displacement of people at Univille, Bom Retiro campus. The study was based on Information Design, Wayfinding, Interaction Design and Usability. The methodology used was called Project E, focused on digitvirtual projects. Thus, the development of the project was structured in the following stages: (1) Strategy; (2) Scope; (3) Structure; (4) Skeleton; (5) Aesthetics; (6) Execution. As a result, a conceptual application has been developed that, if developed and implemented, can contribute to a better orientation of campus users and visitors.

Keywords: Information Design, Wayfinding, Usability. 


\section{Introdução}

Um campus universitário é composto por diversos setores, salas, laboratórios, estabelecimentos comerciais entre outros, dispostos em vias, blocos e quadras distintos. Uma área grande, dotada de tantas opções e possibilidades de acesso necessita de um sistema de localização e sinalização que promova o deslocamento seguro e assertivo das pessoas que o visitam ou que o frequentam regularmente. A motivação para o estudo relatado aqui surgiu da observação das autoras acerca da carência de um sistema de wayfinding eficaz na Universidade da Região de Joinville - Univille. Elas próprias, por vezes, sentiram dificuldade em encontrarem o local desejado ou tiveram que dar informações a diversos visitantes e novos alunos sobre como chegar a uma determinada sala ou laboratório. O sistema atual da universidade não é suficiente para atender às necessidades de deslocamento dentro do campus, pois o mesmo não acompanhou as alterações de salas e crescimento estrutural do campus, não contribuindo para o deslocamento assertivo e seguro de acadêmicos, empregados e visitantes. Sendo assim, o projeto teve como objetivo desenvolver um sistema de wayfinding para a Univille, integrado a um aplicativo para smartphone, de modo a propor uma solução, ainda que conceitual, para a carência identificada pelas autoras. Para isso o projeto estruturou-se nas teorias do Design de Informação e Wayfinding, além do Design de Interação e Usabilidade.

\section{Revisão literária}

O Design de informação pode ser definido como o estudo e a prática de projetar informações visuais claras com o objetivo de direcionar, ensinar, explicar ou informar (LIPTON, 2007). Ou ainda, o design da informação visa configurar a informação, traduzindo dados complexos e desestruturados em mensagens organizadas, acessíveis, úteis e compreensíveis, de modo que satisfaçam as necessidades informacionais dos receptores, em um determinado contexto (IIID, 2014; PETTERSSON, 2010). Assim, para o projeto da informação, destaca-se a importância de se levar em conta quem é o destinatário (foco no receptor), a forma da mensagem (analogia, clareza, concisão, ênfase, coloquialidade, consistência, cordialidade) e o tempo de transmissão da mesma (oportunidade, estabilidade) (REDIG, 2004). O autor (2004) considera como condicionantes mais importantes à mensagem o receptor, a analogia e a oportunidade. Tendo em vista o escopo deste estudo, tem-se como receptor os indivíduos que transitam pela Univille, seja de carro ou a pé, ocasional ou regularmente. Já a analogia que, segundo Redig (2004), deve estar presente ao se tratar o conteúdo da mensagem, visando clareza e rapidez de leitura, neste estudo refere-se à representação da estrutura ou percursos que será utilizada para guiar o deslocamento e sinalizar a localização do usuário. Já, a oportunidade, também citada pelo autor, diz respeito à relevância da mensagem no contexto que está inserida e ao momento em que é apresentada, ou seja, a informação precisa estar disponível, em primeiro plano, quando esta se faz necessária.

Um produto do Design de Informação, ou seja, o veículo de uma mensagem específica, pode atender a diversas funções. Segundo O'Grady (2008), a função pode ser a visualização de dados, contribuindo para a simplificação de conteúdos informacionais complexos e numerosos. Também pode comunicar de modo não verbal, rapidamente, como ocorre com placas de sinalização. Outras possibilidades são simplificar conceitos, contextualizar e auxiliar a visualizar novas conexões. O estudo aqui apresentado abordou diversas das funções citadas, uma vez que propôs um sistema de wayfinding que visa simplificar informações, contextualizar os usuários e comunicar de forma rápida e não verbal (O'GRADY e O'GRADY, 2008). 
Em lugares desconhecidos, é necessário que a informação se apresente, seja ela visual, audível ou tátil, não somente para liderar o caminho, mas também para garantir que o usuário se locomova com segurança e assertividade. Assim, o wayfinding é um processo que abrange a experiência de escolher um caminho dentro de um ambiente construído e o conjunto de elementos de design que ajudam em tal decisão (GIBSON, 2009). Segundo Mollerup (2005), o processo de Wayfinding compreende três etapas: (1) busca, (2) decisão, (3) movimento. Na primeira etapa o usuário busca a informação de sua localização e itinerário. Na segunda, decide o caminho a seguir e, por fim, se movimenta na direção escolhida.

No caso de um sistema de wayfinding integrado a um smartphone, torna-se importante conhecer aspectos teóricos e diretrizes do Design de Interação, pois é interagindo com o sistema que o usuário poderá acessar as informações.

Preece et al. (2005) oferecem uma abordagem prática e orientada do processo de design de interação, mostrando princípios e como aplicá-los. Por exemplo, como entender o usuário, entender o desenvolvimento do design de informação, como identificar e estabelecer requisitos para o projeto, entre outros, focando na diversidade dos processos de design e de avaliação dos envolvidos. Por meio de técnicas apresentadas, como de coleta de dados, observação, análise e interpretação, é explicado o caminho de um processo de design para chegar a um sistema interativo. Neste estudo foram identificados os requisitos funcionais que o aplicativo deve ter, são as tarefas que devem ser realizadas para cumprir seu objetivo. Ao se falar em sistema interativo, não se pode deixar de abordar a usabilidade. Esta, de acordo com Cybis e Betiol (2007), é que torna possível o uso de programas e aplicações. Ainda assim, a usabilidade não é uma característica intrínseca de um sistema, mas é diretamente influenciada por características da interface, do usuário, da tarefa e do ambiente.

A norma ISO 9241 (apud CYBIS e BETIOL, 2007, p. 15) define Usabilidade como "a capacidade que um sistema interativo oferece a seu usuário, em determinado contexto de operação, para a realização de tarefas de maneira eficaz, eficiente e agradável". Segundo Nielsen (1994), a usabilidade se aplica a todos os aspectos de um sistema com os quais o usuário possa interagir e possui múltiplos componentes, são eles: capacidade de aprendizado (learnability); eficiência (efficiency); capacidade de memorização (memorability); erros (errors); satisfação (satisfaction).

A usabilidade é tipicamente avaliada por meio de testes com usuários com características que representam o público pretendido. Nielsen (1994) elaborou dez heurísticas para evitar erros básicos de usabilidade, com base em vários testes realizados com sistemas diversos, são elas: visibilidade de qual estado estamos no sistema; correspondência entre o sistema e o mundo real; liberdade de controle fácil para o usuário; consistência e padrões; prevenção de erros; reconhecimento em vez de memorização; flexibilidade e eficiência de uso; estética e design minimalista; ajuda aos usuários no reconhecimento, diagnóstico e recuperação de erros; ajuda e documentação.

\section{Método e etapas de desenvolvimento do projeto}

Considerando-se o objetivo da pesquisa aqui relatada e sua característica digital, adotou-se - método Projeto $E$, voltado para projetos dígito-virtuais, composto por seis etapas correlacionadas (MEURER e SZABLUK, 2010): (1) Estratégia, que prevê a contextualização do projeto; (2) Escopo, etapa em que ocorre a organização das informações; (3) Estrutura, onde são 
elaborados organogramas e fluxogramas das tarefas; (4) Esqueleto; que compreende a organização estrutural das telas da interface, por meio dos wireframes; (5) Estética, em que é elaborada a composição final do conteúdo e a identidade gráfico-visual; (6) Execução, etapa em que são desenvolvidos modelos interativos que simulam as principais funcionalidades do produto, com vistas à realização de testes de usabilidade. Considerando-se essas etapas, o projeto desenvolveu-se conforme descrito a seguir.

\subsection{Etapa 1: Estratégia}

De modo a ter uma visão do contexto do projeto e de buscar bases para o estabelecimento de requisitos para o desenvolvimento do aplicativo, esta primeira etapa compreendeu questionário com público alvo, análise de similares e lista de verificação.

O questionário teve como objetivo, conhecer as necessidades, dificuldades e as rotas usuais utilizadas pelos alunos ao se locomoverem dentro do campus da Univille. O link do formulário online foi enviado por email às coordenações de cursos diversos da instituição, localizados em diferentes pontos da universidade, e então, foi encaminhado aos acadêmicos, privilegiando-se turmas do $1 \mathfrak{0}$ ano, porém não limitando-se a estas. Ao todo foram 144 participantes. A partir das respostas confirmou-se que os acadêmicos de séries iniciais têm mais dificuldade de localizar-se dentro do campus. Além disso, foi possível conhecer os lugares mais frequentados e os mais difíceis de serem encontrados pelos estudantes. A partir do questionário também identificou-se os aplicativos semelhantes mais utilizados pelos participantes, o que contribuiu com a seleção para a análise de similares.

A fim de conhecer softwares com objetivos similares ao proposto para este projeto, realizou-se uma análise qualitativa, considerando-se características gráficas, informacionais e de interação dos aplicativos mais utilizados pela amostra participante do questionário. Foram, então, analisados os layouts e funcionalidades dos aplicativos: Google Maps, Moovit e Waze. Como resultado, foi possível identificar particularidades destes, como posicionamento de botões, cores, público a que se destina, funções principais, estrutura, modo de interação do usuário.

A partir dos pontos levantados com a análise de similares desenvolveu-se uma lista de verificação. Esta teve como objetivo estabelecer requisitos para o desenvolvimento do projeto prático. Assim, foram elencados pontos positivos e negativos dos aplicativos, vantagens, diferenciais e usabilidade, de modo a guiar o desenvolvimento do aplicativo proposto.

\subsection{Etapa 2: Escopo}

Tomando-se como base a etapa de Estratégia (1), definiu-se o conceito e o posicionamento gráfico-visual do produto. Assim, o aplicativo conceitua-se como um guia dentro do campus, com um visual minimalista e amigável, utilizando linguagens verbal e visual simples e direta, de modo que possa ser utilizado por pessoas de diferentes perfis, sem necessidade de um manual.

O conceito surgiu a partir de análises de aplicativos similares e da síntese das informações obtidas com a realização de questionário, identificando-se as necessidades do público. Ainda sobre o público, foi analisado o contexto que ele se encontra (idade, locais frequentados na universidade, utilização de aplicativos em smartphone) e com isso definiu-se o estilo a ser seguido.

A partir do conceito e levando-se em conta as heurísticas propostas por Nielsen (1994), desenvolveu-se uma lista de características/funções obrigatórias e desejáveis, conforme segue. Entre as obrigatórias estão: ícones e botões simples, de fácil percepção; poucos elementos; cores 
uniformes; mapa; barra de pesquisa; indicação do caminho a ser percorrido; ícones indicando locais principais; lista de locais principais; lista de salas em cada andar de cada bloco; marcação dos locais favoritos; lista de locais mais acessados; seu local-destino. As características/funções classificadas como desejáveis foram: botão para usuários adicionarem foto do local; botão para usuários adicionarem comentários sobre o local; auxílio para deficientes visuais (comando de voz, aviso direção por voz); compartilhamento externo do local visitado, via Whatsapp, Messenger ou outros recursos comumente utilizados em aplicativos similares.

\subsection{Etapas 3 a 6: Estrutura, Esqueleto, Estética e Execução}

Na etapa 3, Estrutura, foi desenvolvido o organograma geral e os fluxogramas de todas as tarefas previstas para o produto (Figura 1), visando a organização hierárquica destas e de outras informações do aplicativo. 
Login
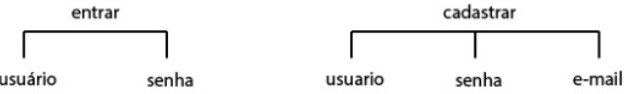

Inicio

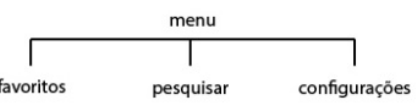

favoritos pesquisar configuraçōes

botäo iniciar

trajeto
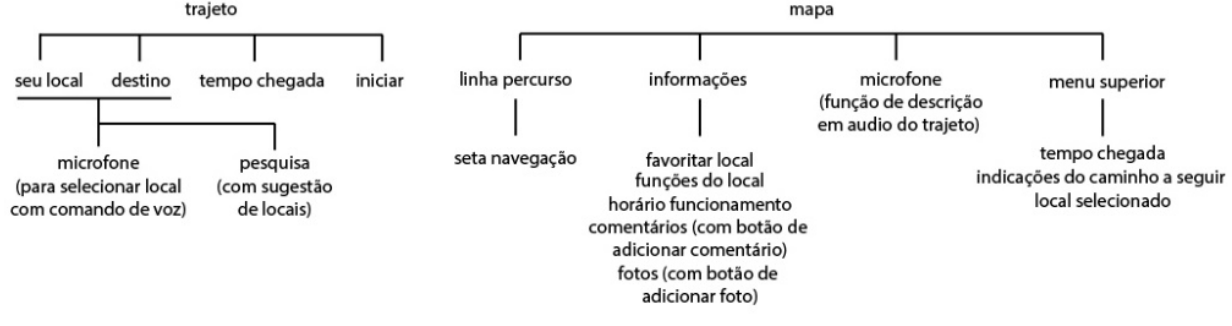

botão favoritos

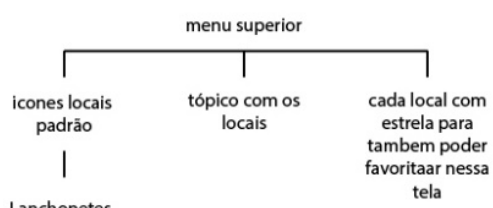

Lanchonetes,

Departamentos,

administrativos,

salas de aula,

outros, favoritos

botão configuraçōes

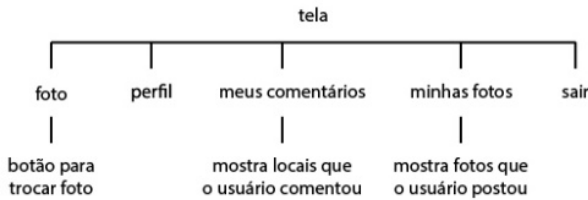

A etapa seguinte, denominada Esqueleto, teve como objetivo definir aspectos estruturais e arquiteturais do aplicativo. Assim, compreendeu a geração de alternativas de wireframes e funções, definindo-se o posicionamento de cada uma destas dentro do aplicativo. Como resultado, obteve-se 14 (quatorze) telas (figura, entre elas: Login; Cadastro; Início; Pesquisa de trajeto; Iniciar trajeto; Rota; Informações; Adicionar foto; Favoritos; Configurações; Meus comentários; Minhas fotos.

A etapa 5, Estética, teve como objetivo definir aspectos visuais da interface gráfica do aplicativo. Assim, a partir de geração de alternativas foi possível definir: estilo dos botões; cores; imagens; nome e logotipo do aplicativo (figura 2). Tanto as cores como ícones e botões foram definidos após análise de similares (etapa 1 - Estratégia) e pesquisas visuais de aplicativos encontrados em plataformas digitais.

Figura 2 - Cores e ícones definidos 


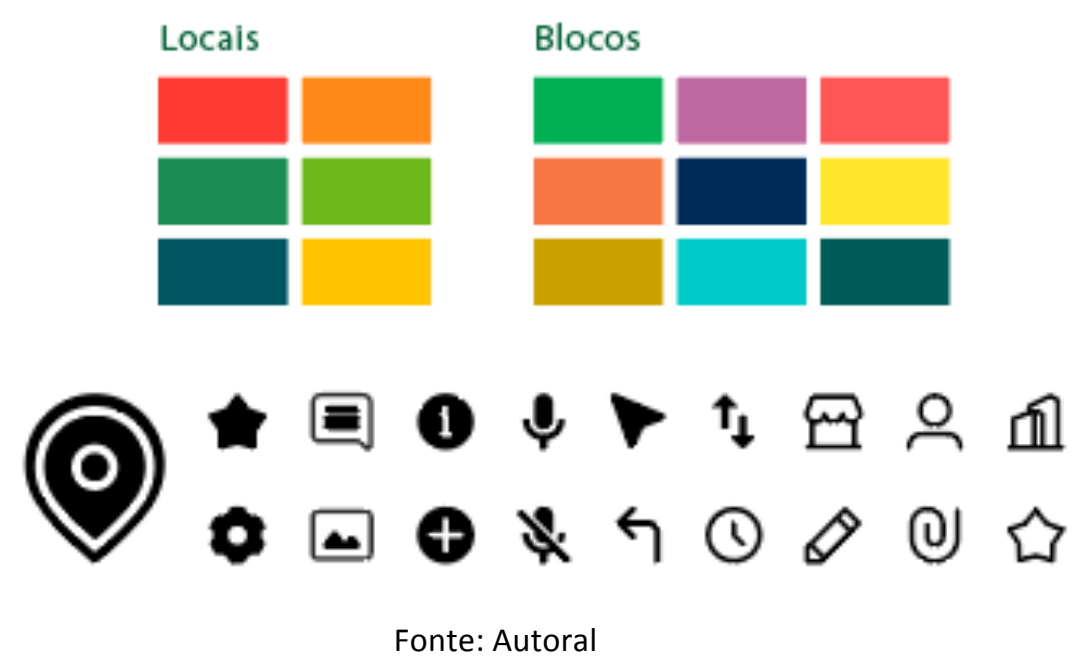

$\mathrm{Na}$ etapa 6, Execução, foi previsto o desenvolvimento de um protótipo (figura 3) do aplicativo para a realização de um teste de usabilidade com acadêmicos de áreas e idades diversas. O protótipo simulando funções do aplicativo foi desenvolvido, porém não foi possível fazer o teste de usabilidade, devido a uma alteração no cronograma da pesquisa. 


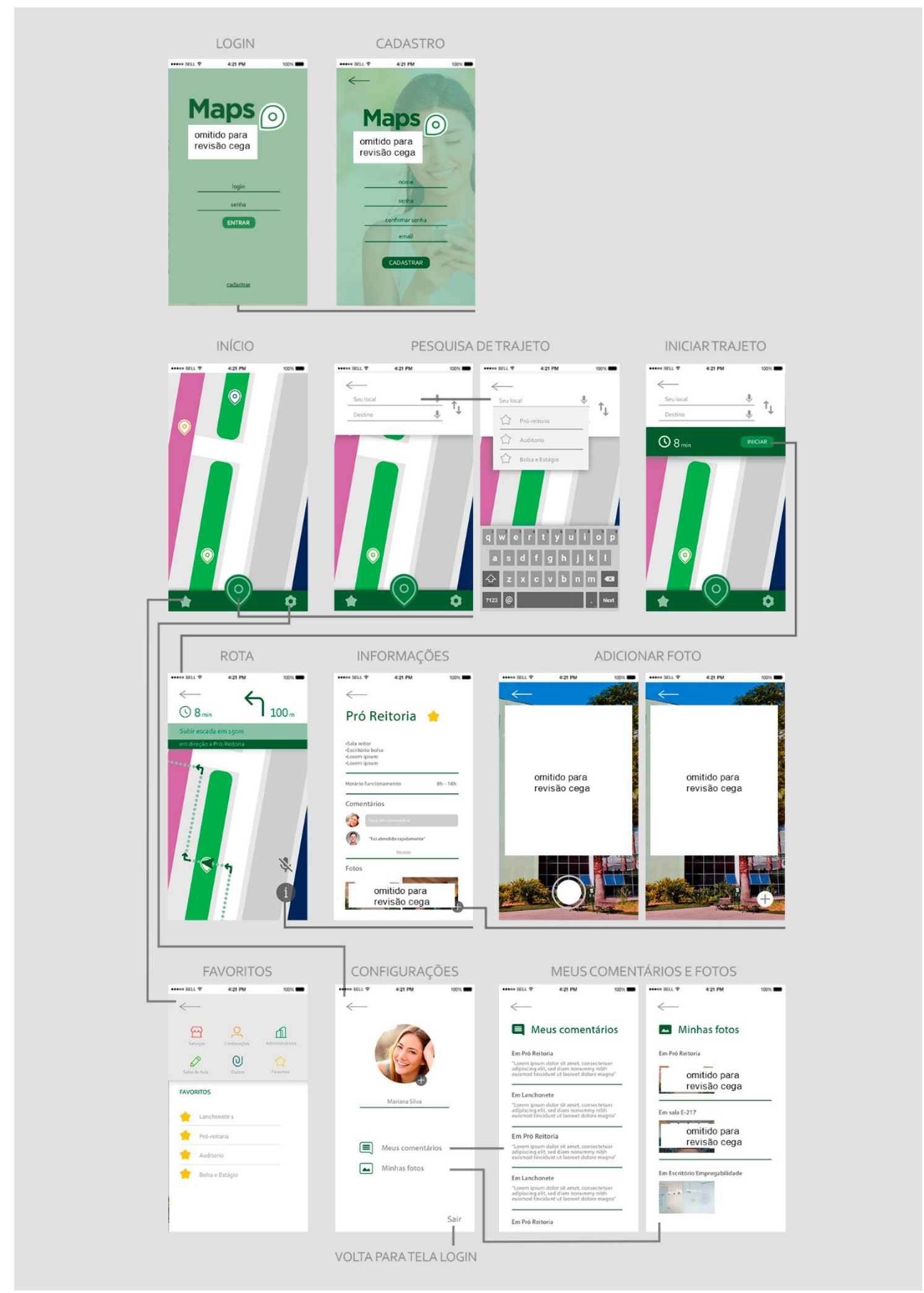

Fonte: Autoral. Disponível em: https://invis.io/TZEZP5OEB 


\section{Discussão dos resultados}

O aplicativo desenvolvido teve como fundamentos as teorias do Design de Informação, com foco em Wayfinding, e do Design de Interação e Usabilidade. Resgatando-se as condicionantes mais importantes à mensagem, consideradas por Redig (2004) - receptor, analogia e oportunidade, pode-se dizer que o projeto levou em conta cada uma delas ao pesquisar sobre o público-alvo (receptor), ao adotar a representação esquemática e o acompanhamento do percurso do usuário em tempo real (analogia) e ao ser aplicado a um fim específico, considerandose a necessidade percebida (oportunidade).

Tendo em vista os critérios de Usabilidade, tomou-se como base as dez heurísticas elencadas por Nielsen (1994). Desse modo, relacionando-as ao aplicativo conceitual criado, o Maps Univille oferece ao usuário (1) visibilidade de seu estado no sistema; (2) correspondência entre o sistema e o mundo real e (3) reconhecimento ao invés de memorização, pois oferece atualização por GPS em tempo real, de acordo com o deslocamento do usuário, além do desenho esquemático dos caminhos do campus; (4) liberdade de controle fácil para o usuário, uma vez que os ícones utilizados possuem características que os diferenciam uns dos outros, facilitando sua identificação e diminuindo a possibilidade de o usuário confundi-los, além das diversas ferramentas para interação com o sistema que o aplicativo oferece e possibilidades de acesso a qualquer momento; (5) consistência e padrões, por meio de estilo e cores que se estendem a todas as telas do aplicativo; (6) prevenção de erros, pois permite que o usuário retorne a outras páginas e funções sempre que desejar; (7) estética e design minimalista, pois o layout proposto inclui somente elementos essenciais à representação da informação, de modo que esta possa ser compreendida rapidamente; (8) ajuda aos usuários no reconhecimento, diagnóstico e recuperação de erros pois se um caminho não foi selecionado corretamente o aplicativo avisa, ou também se o usuário estiver na rota errada, o aplicativo vai recalcular o melhor caminho a seguir; (9) ajuda e documentação, quando sugere locais após o usuário começar a escrever na barra de pesquisa; (10) flexibilidade e eficiência de uso. Em relação à flexibilidade do aplicativo destacam-se as diversas possibilidades de interação com o mesmo, permitindo comando por texto, por meio dos botões ou por voz; o compartilhamento de informações e fotografias; a classificação dos locais visitados etc. Já em relação à eficiência, não se pode afirmar com certeza, uma vez que o teste de usabilidade não foi realizado.

\section{Considerações Finais}

Um projeto de Design de Informação necessita ser centrado no usuário, uma vez que a informação depende deste para se concretizar. Além disso, há que se considerar outros fatores, que são a mensagem propriamente dita, a representação desta e o meio em que ela será transmitida. A partir do estudo realizado, pode-se dizer que um projeto de sinalização e wayfinding, particularmente, requer conhecimentos específicos que abordam o ambiente construído (contexto em que se aplica o sistema), o público-alvo (receptor), as possibilidades de representação (analogia), a natureza da mídia utilizada (suporte), as informações necessárias para o deslocamento assertivo (oportunidade).

O público-alvo foi inserido no projeto por meio do questionário realizado com acadêmicos da universidade, o que contribuiu significativamente para identificar os locais que eles mais sentem dificuldade em encontrar dentro do campus. Essa ferramenta também contribuiu para se compreender o público que utilizaria o aplicativo e suas rotas usuais no campus, e para se 
identificar as necessidades dos acadêmicos quanto ao problema mencionado.

Levando-se em conta o suporte do sistema proposto, de natureza digital (smartphone), optou-se por não utilizar um método específico para projetos de wayfinding. Assim, julgou-se mais interessante utilizar o Projeto E. O método escolhido contribuiu para o desenvolvimento projetual pois norteou o estudo com foco em um produto digital, auxiliando a desenvolver estudos, análises e verificações, a conceituar o projeto e a definir sua estrutura e funções.

Apesar da proposta não prever a implantação real do sistema, acredita-se que esta poderia ocorrer. Para tanto, deveriam ser realizados testes de usabilidades a partir do protótipo criado, além de outros estudos técnicos, relacionados ao desenvolvimento do software propriamente dito.

\section{Referências}

CYBIS, Walter de Abreu, BETIOL, Adriana Holtz \& FAUST, Richard. Ergonomia e Usabilidade: conhecimentos, métodos e aplicações. 2. ed. São Paulo: Novatec Editora, 2010.

GIBSON, David. Wayfinding handbook: the information design for public places. Princeton: Princeton Architecture, 2009.

IIID - International Institute of Information Design. Core competencies: what information designers know and can do. 2007 Disponível em:<http://www.iiid.net/PublicLibrary/idX-CoreCompetencies-What-information-designers-know-and-can-do.pdf $>$. Acesso em: 10 de out. de 2017.

MEURER, H.; SZABLUK, D. Projeto E: aspectos metodológicos para o desenvolvimento de projetos dígito-virtuais. Revista Ação Ergonômica, v. 5, n. 2, 2010.

MOLLERUP, Per. Wayshowing wayfinding, basic \& interactive. Amsterdã: Bis Publishers, 2005.

NIELSEN, Jacob. Usability engineering. San Francisco: Morgan Kaufman, 1994.

PETERSSON R. Information design: an introduction. Amsterdã: John Benjamins Publishing Company, 2010

PREECE, J., ROGERS, Y., SHARP, H. Design de Interação: além da interação homem-computador. Porto Alegre: Bookman, 2013.

O'GRADY, J.; O'GRADY, K. The Information Design Handbook . Londres: Rotovision, 2008.

REDIG, Joaquim. Não há cidadania sem informação e nem informação sem design. InfoDesign Revista Brasileira de Design da Informação v. 1, n. 1, 2004, p. 58-66 ISSN 1808-5377. 